\title{
ASPECTOS MÉTRICOS Y FORMALES DE LA TRADICIÓN POÉTICA ÁRABE EN EL DIVÁN DEL TAMARIT, DE FEDERICO GARCÍA LORCA
}

\section{METRIC AND FORMAL ASPECTS OF ARABIC POET- IC TRADITION IN FEDERICO GARCÍA LORCA'S DIVÁN DEL TAMARIT}

\author{
Begoña Molina Prieto \\ Universidad de Sevilla
}

\begin{abstract}
Resumen: En este trabajo se abordan las relaciones métricas entre el Diván del Tamarit y la poesía arábigo-andaluza. Además del análisis métrico, el objetivo también es comprobar qué uso hace Lorca de las denominaciones literarias árabes: diwan, qasida y gacela. La importancia de este estudio radica en comprobar el acercamiento palpable que se observa en el Diván del poeta granadino hacia la tradición poética árabe, pero siempre manteniendo una poética lorquiana. Para llevarlo a cabo se han utilizado fundamentalmente tres obras árabes: los Poemas arábigoandaluces del arabista Emilio García Gómez, a través de quien Lorca conoció los poemas de Ibn Hazm, Ibn Suhayd, Ibn Zamrak o Ibn Zaydun, entre otros; El mejor Ben Quzmán en 40 zéjeles, también editada y traducida por el mismo autor, y las Casidas selectas de Ibn Zaydun, traducidas y editadas por Mahmud Sobh.
\end{abstract}

Palabras clave: poesía, métrica, Federico García Lorca, poesía árabe andalusí.

Abstract: This article shows a comparative metrical study of Diván del Tamarit and Arabic-Andalusian poetry. In addition to 
the metric analysis, the goal is also cheking the use that Lorca makes of Arabic literary names, such as: diwan, qasida and gacela. The most important search of the present study is to prove the close proximity of Lorca's Diván with Arabic poetic tradition, but always keeping a defined lorquian poetic style. To achieve this goal I have essentially used three Arabic poetry works: Poemas arábigoandaluces by the Arabist Emilio García Gómez, through whom Lorca knew the poetry of Ibn Hazm, Ibn Suhayd, Ibn Zamrak or Ibn Zaydun, among others; El mejor Ben Quzmán en 40 zéjeles, also translated and released by the same author, and Casidas selectas by Ibn Zaydun, translated and released by Mahmud Sobh.

Key words: poetry, metrics, Federico García Lorca, Andalusi Arabic Poetry. 


\section{Introducción}

1 estudio comparativo entre Lorca y los poetas arábi-
go-andaluces surge a partir de una relación palpable: la
lectura por parte de García Lorca de la obra de Emilio
García Gómez, Poemas arábigoandaluces, así como de la edición de las Poesías asiáticas del Conde de Noroña. Por tanto, existe en primer lugar una relación de hecho -en consonancia con las ideas de la «escuela francesa»-. Sin embargo, una vez estudiada y comprobada esa primera relación de hecho, se han tenido en cuenta no solo las orientaciones metodológicas de la escuela francesa, en la que implícitamente se presupone la influencia de una obra sobre otra, sino que dejando a un lado el concepto mecanicista de influencia, he considerado también otros planteamientos metodológicos, sobre todo a partir de las críticas de Claudio Guillén respecto de las relaciones de hecho y su visión de la influencia cuando entiende esta como concepto positivista: «una influencia representa el paso ininterrumpido de una cosa a otra», explica el crítico, de manera que la segunda obra queda supeditada a la primera -la cual motivaría su aparición ${ }^{1}-$. Así, pues el estudio de la influencia en un sentido meramente historicista no es el enfoque de este artículo; no se puede hablar sin más de una relación de influencia entre estas literaturas, puesto que el autor granadino elaboró un poemario a su propia manera y no a la de los poetas árabes. Prueba de lo que se dice es el hecho de que Lorca no siga los patrones métricos de las gacelas y casidas, como veremos a lo largo de este artículo. De esta manera, el autor granadino homenajea a los antiguos poetas de al-Ándalus, llamando a sus poemas gacelas y casidas, pero sin seguir los moldes métricos árabes.

${ }^{1}$ Guillén, Claudio: Entre lo uno y lo diverso. Barcelona: Tusquets, 2005, pp. 82 y 83. 


\section{La importancia de la tradición poética en Federico García Lorca}

Sabida es la importancia que tiene para el poeta Federico García Lorca la recogida y la asimilación de la tradición lírica popular en su poesía, siempre con el interés de incluirla dentro de su poética, sirviéndole de retroalimentación, para combinarla con una imaginería y una técnica más modernas. Sus composiciones poéticas, así como las estrofas populares y tradicionales quedan verdaderamente conjugadas y ensartadas dentro de su nueva poesía, de manera que se puede hablar de «un acuerdo - en palabras de Luis Cernuda- entre la métrica del pasado y la nueva ${ }^{2} \gg$. Es en este sentido en el que debe entenderse el Diván del Tamarit, un ejercicio más por parte del poeta granadino de recoger otras poéticas anteriores a él, en este caso la arábigoandaluza -sin desdeñar la persa-. Así, Lorca se vale también de la métrica arábiga y persa para desarrollar la suya y escribir su propio Diwān; sin embargo, como se ha dicho anteriormente, no se atañe a las reglas métricas de la qasida y la gacela, tan solo las utiliza como un consciente homenaje a los poetas andalusíes. Esas denominaciones están tomadas intencionadamente para evocar la tradición árabe, a través de ellas emerge en el texto la literatura árabe y persa, aparece, pues, el elemento extranjero, como lo denomina Pierre Brunel, gracias a algunas palabras que consiguen, a través de las imágenes producidas, remitirnos a otras tradiciones alejadas y ajenas ${ }^{3}$.

El hecho de que Lorca vuelva su mirada hacia la tradición árabe debe entenderse en el sentido de que bebe de una tradición afincada en la propia historia literaria española. Cabe recordar aquí, pues, de manera muy breve, ya que no es el objeto del presente artículo, la teoría del origen arábigo-andaluz de ciertas composiciones de la lírica románica, emitida esta por el arabista Ribera ${ }^{4}$ y defendida también por Gaspar María de Navas en la

${ }^{2}$ Cennuda, Luis: Poesía española contemporánea. Madrid: Guadarrama, 1975, p. 164.

${ }^{3}$ BRunel, Pierre: «El hecho comparatista», en Brunel, Pierre y Chevrel, Yves (ed.): Compendio de Literatura Comparada. México: Siglo XXI, 1994, pp. 21-50.

${ }^{4}$ Según explica Ángel González Palencia, su tesis fue recibida con recelo. Vide GonZÁlez PAlencia, Ángel: «La poesía arábigo andaluza y su influencia», Revista Hispánica Moderna, 1935, I, 2, p. 93. 
introducción a sus Poesías asiáticas, así como Ramón Menéndez Pidal, entre otros críticos. El padre Juan Andrés, en su obra Origen, progresos y estado actual de toda la literatura, abogaba por esta teoría del origen árabe de la métrica trovadoresca. Así, por ejemplo, quedaba asociada la canción con la estrofa zejelesca, considerada por los arabistas, junto con otras composiciones poéticas, «el origen de la poesía estrófica europea ${ }^{5} »$.

\section{El Diwān y el Cancionero}

En primer lugar, hay que partir de las claras diferencias que existen entre la métrica española y la árabe. Basándose la primera en el ritmo intensivo o acentual y en el número de sílabas y no en el cuantitativo, como la árabe, la persa, la latina o la griega, las distinciones serán inevitablemente considerables. Cabe advertir aquí la importancia que tiene para teóricos literarios como Isabel Paraíso, Domínguez Caparrós o Esteban Torre el ritmo en la poesía y más concretamente en la española ${ }^{6}$. Así pues, no resulta posible asimilar la forma métrica hispánica a la cuantitativa, ni ajustar su sistema métrico silábico al compuesto por sílabas largas y breves, como explica Antonio Quilis ${ }^{7}$, pues son características que se encuentran dentro del sistema métrico de esos pueblos y no se corresponden con la condición intrínseca de otros como el nuestro. «El distinto carácter de las lenguas y el margen de convencionalidad explican los diferentes sistemas de versificación», expone Domínguez Caparrós, y añade que algunas lenguas tienden a la «isocronía de los pies acentuales», mientras que «otras se organizan con isocronía silábica y anisocronía acentual». En efecto, puede hablarse más de una tendencia que de una realidad y una división absoluta ${ }^{8}$. Sin embargo, hay que tener en cuenta también la opinión de otros versólogos,

\footnotetext{
${ }^{5}$ VERnET, Juan: La cultura hispanoárabe en Oriente y Occidente. Barcelona: Ariel Historia, 1978, p. 282.

${ }^{6}$ Los elementos encargados de generar ritmo son: «la longitud del verso computada en número de sílabas (metro), la distribución de los acentos dentro del metro, la rima o marca final del verso, y la posible existencia de estrofas en bastantes tipos de poemas»), sin olvidar las pausas (PARAíso, Isabel: La métrica española en su contexto románico. Madrid: Arco / Libros, 2000. p. 27).

${ }^{7}$ Quilis, Antonio: Métrica española. Barcelona: Ariel, 2009, p. 21.

${ }^{8}$ Domínguez Caparrós, José: Métrica española. Madrid: Síntesis, 2000. p. 42.
} 
como Esteban Torre, quienes han discutido estos conceptos, así como la división de lenguas acentuales y lenguas silábicas, pues consideran que la tradición literaria occidental demuestra que se dan modelos de una normalidad silábica absoluta en lenguas pretendidamente acentuales, como la alemana o la rusa, por ejemplo ${ }^{9}$.

Sea como fuere, la norma métrica para la poesía árabe clásica aboga por tiradas de versos largos monorrimos, teniendo en cuenta la cantidad de sílabas largas y breves que contengan ${ }^{10}$. Además de la cantidad, en la métrica árabe y persa es destacable el uso de la rima en el poema como elemento de cohesión entre los versos. En persa clásico «hacer un poema» significa, metafóricamente hablando, «ensartar perlas», por lo que el poema es concebido por el autor como una sucesión de dísticos enlazados cada uno, de manera visible, a través de una rima ${ }^{11}$.

La palabra Diwān proviene del árabe y se utiliza para hacer referencia a la colección de poemas de un determinado autor. Generalmente se ordenan estos de manera alfabética, según la rima que posean, dependiendo de la última letra en la que acabe el primer verso de cada poema ${ }^{12}$. Asimismo, los cancioneros son también recopilaciones de poemas de un autor o varios.

La qasida, por su parte, es un poema monorrimo, es decir, mantiene la misma rima -siempre consonante-durante toda la composición poética. Su extensión no se encuentra fijada, según explica Josefina Veglison Elías de Molins, «oscila entre unos treinta y cien versos ${ }^{13} \gg$. La métrica árabe está basada en la medición de pies y de sílabas largas y breves, al igual que en latín y griego, por lo que su sistema métrico es cuantitativo. Cada verso

${ }^{9}$ Véase Torre, Esteban: El ritmo del verso (Estudios sobre el cómputo silábico y la distribución acentual, a la luz de la Métrica comparada, en el verso español moderno). Murcia: Universidad de Murcia, 1999, pp. 27ss.

10 Alvar, Carlos: «Poesía culta y tradicional», en Pedro M. Piñero Ramírez (ed.): Lírica popular / Lírica tradicional. Lecciones en homenaje a D. Emilio García Gómez. Sevilla: Universidad de Sevilla, Fundación Machado, 1998, p. 100.

${ }^{11}$ BACKĖs, Jean-Louis: «Poética comparada», en Brunel, Pierre y Chevrel, Yves (ed.): Compendio de Literatura Comparada, cit., p. 53.

${ }^{12}$ Nava, Gaspar María de, Conde de Noroña (ed. y tr.): Poesías asiáticas. París: Julio Didot Major, 1833; segunda edición, Madrid: Biblioteca Universia, 1882, p. 241.

13 Veglison Elías De Molins, Josefina: La poesía árabe clásica. Madrid: Hiperión, 1997, p. 29. 
se encuentra formado por dos hemistiquios, cada uno separado por una cesura y estos riman entre sí. Esa división del verso en dos puede recordar al lector hispano al verso endecasílabo común, donde el acento principal se encuentra hacia la mitad del verso, en el sexto, además de en el décimo; de manera que el verso logra un ritmo ${ }^{14}$ determinado que podría acercarse al de las qasidas. Si bien es cierto que el endecasílabo carece de esa cesura interna.

Volviendo a la qasida, temáticamente se divide en tres partes:

-Nasīb o prólogo amoroso, donde el autor recuerda los momentos vividos junto con la persona amada.

- Rahīl, donde se realiza una descripción de un viaje.

-Madīh, se trata del elogio emitido por el poeta a los jeques, a la tribu o a un amigo, al finalizar el viaje y llegar al lugar deseado. Además, puede dedicarse también un elogio a sí mismo, conocido con el nombre de fajr.

La consecuencia de esta división es el nacimiento de la gacela, que puede decirse que surge a partir del nasīb de la qasi$d a$. En ella, esa división tripartita de temas no existe, sino que enteramente va dedicada al amor, ya sea un elogio, un llanto o un reproche. Es también un poema monorrimo, donde los dos primeros versos deben ser consonantes entre sí o terminar con la misma palabra, la cual deberá repetirse en el final de todos los pares. Cada verso tendrá un sentido distinto y, por tanto, una independencia semántica con respecto al resto de versos que constituyen el poema, al igual que ocurre en la qasida ${ }^{15}$.

A continuación, se puede leer en versión original un poema de Ibn Zaydun, como ejemplo ilustrativo de la disposición métrica y estrófica de la casida árabe:

\footnotetext{
$\overline{{ }^{14}}$ El ritmo es el rasgo más importante de la poesía. Como expone Domínguez Caparrós, el ritmo domina la organización interna de la poesía. Véase DoMínguEZ Caparrós, José: Métrica española, cit., p. 26.

${ }^{15}$ Nava, Gaspar María de, Conde de Noroña: Poesias asiáticas, cit., pp. 237 y 238.
} 


$$
\begin{aligned}
& \text { انى اضيع عهلك ام كيف /خلف وعدك } \\
& \text { وقد راتك الاماني رضي على فلم تتعدك }
\end{aligned}
$$

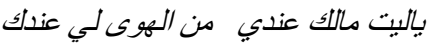

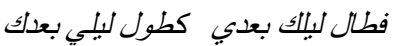

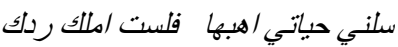

$$
\begin{aligned}
& \text { الدهر عبدي لما اصبحت في احلب عبلك } 16
\end{aligned}
$$

Resulta conveniente incluir la versión original puesto que, por las condiciones lingüísticas y gráficas de nuestra lengua, sería imposible una traducción en la que se pudiera comprobar esa rima característica de la casida. Así se puede observar cómo cada verso queda dividido en dos partes bien diferenciadas -hemistiquios-, las cuales aparecen separadas de manera visual por el propio autor, y su rima siempre es la misma, desde el principio hasta el final. En este caso, la letra ك la encargada de regir la rima de toda la tirada de versos. Como se ha adelantado y se puede comprobar al realizar la lectura del Diván del Tamarit, García Lorca no sigue los parámetros métricos de la casida y la gacela; sin embargo, sí existen dos poemas en los que la característica de la monorrima se cumple, lo cual recuerda indudablemente a este tipo de composiciones estróficas arábigas. Uno de ellos es el siguiente:

La muchacha dorada se bañaba en el agua y el agua se doraba.

Las algas y las ramas en sombra la asombraban, y el ruiseñor cantaba por la muchacha blanca.

Vino la noche clara, turbia de plata mala, con peladas montañas bajo la brisa parda.

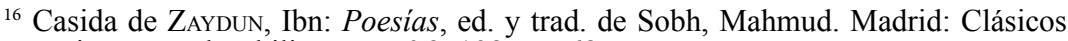
Hispano-árabes bilingües, n. ${ }^{\circ} 2,1985$, p. 68. 
La muchacha mojada era blanca en el agua y el agua, llamarada.

Vino el alba sin mancha, con cien caras de vaca, yerta y amortajada con heladas guirnaldas.

La muchacha de lágrimas se bañaba entre llamas, y el ruiseñor lloraba con las alas quemadas.

La muchacha dorada era una blanca garza y el agua la doraba ${ }^{17}$.

No solo el poema es monorrimo, sino que además la aliteración de la vocal $a$ es clara en todos los versos. Aunque propiamente no pueda hablarse de agrupaciones estróficas diferenciadas en el poema, pues la rima idéntica en todos los versos lo impide, el poema lorquiano está agrupado sintácticamente en tercetos y cuartetos. Al ser versos heptasílabos, de arte menor, se podría hablar de tercetillos y cuartetas, aunque la rima, de base asonante aquí, como se ha mencionado ya, es siempre monorrima. Serían, por tanto, agrupaciones pseudo-estróficas, ya que la rima no varía a lo largo del texto. Sin embargo, estas agrupaciones sí tienen un sentido y una funcionalidad en el poema. Los tercetillos quedan vinculados con la soledad de la joven en su relación e identificación con el agua. Los recursos a la reiteración y al paralelismo en los tercetillos contribuyen, en el plano formal, como la rima, a este mismo efecto semántico de unidad con el agua, a modo de estribillo con variaciones. Si se consideran los versos separadamente, podrá observarse mejor esta unidad semántica y formal:

${ }^{17}$ García Lorca, Federico: "Casida de la muchacha dorada», en Diván del Tamarit, edición crítica de Andrew A. Anderson. Madrid: Espasa Calpe, 1988, pp. 245, 246 y 247. En adelante, utilizaré esta edición. 
verso 1

la muchacha dorada

la muchacha mojada

la muchacha dorada verso 2

se bañaba en el agua

era blanca en el agua

era una blanca garza verso 3

y el agua se doraba

y el agua, llamarada

y el agua la doraba

El contraste entre la agrupación sintáctica de las estrofas tampoco es casual. Mientras los tercetillos monorrimos ofrecen la imagen estática de la muchacha, las cuartetas monorrimas suponen el contraste con elementos externos a la identificación de la joven y el agua, con la idea de acción y de movimiento progresivo que, igualmente es potenciada por los recursos de la repetición y del paralelismo: la presencia de la sombra en contraposición a la claridad, la irrupción del ruiseñor, la llegada de la noche, la llegada del alba, la presencia nuevamente del ruisenor para anunciar, en correspondencia con la imaginería de las estrofas anteriores, la separación y la muerte.

El poema bebe en gran medida de la métrica popular. No se debe olvidar, en este sentido, que el verso de arte menor más utilizado en poesía española es el octosílabo. Este aparece en las jarchas, en coplas, soleares, décimas, redondillas, en el Romancero, etc. Así, la mayor parte de la lírica popular está escrita en versos de ocho sílabas, aunque también es muy frecuente el heptasílabo ${ }^{18}$. Aparte de la existencia de agrupaciones estróficas monorrimas en la tradición occidental, conviene tener en cuenta el acercamiento a la tradición literaria árabe clásica que conlleva ese mantenimiento de la misma rima en todos los versos. Al leer y analizar el poema, se observa una evidente disposición por parte de García Lorca de valerse de la métrica popular para nutrir la suya propia, una métrica en la que la canción -con las coplas y las soleares-son de gran relevancia. Realmente, aquí no puede hablarse estrictamente de coplas o soleares, pues prescinden de la rima habitual asonante con versos sueltos. El poeta granadino, siguiendo con su afán por homenajear a sus antepasados y siendo fiel a su condición de poeta del pasado, del presente y del futuro, decide tener en cuenta la tradición arábigo-andaluza, la cual no es ajena tampoco a la canción popular, y, así, introduce la característica de la monorrima en su poema -tan propia de la poesía árabe y persa-, valiéndose,

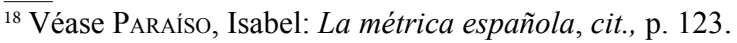


además, de la aliteración fónica de la vocal $a$. De esta manera, opta por mantener durante todo el poema la rima asonante continuada, con la que logra un mayor efecto de musicalidad, al igual que ocurre en las composiciones poéticas árabes y persas.

En este sentido, se pueden hallar las conexiones entre la métrica del Diván del Tamarit y la poesía árabe andalusí, siempre teniendo en cuenta la no adopción por parte de Lorca de los parámetros métricos árabes, pues se trata de poemas totalmente lorquianos ${ }^{19}$. Por tanto, mientras que homenajea a los poetas de al-Andalus, adapta fácilmente esas composiciones estróficas según su métrica y su poética ${ }^{20}$, la cual está constituida por la tradición del pasado y unos parámetros métricos enfocados hacia la modernidad, donde siempre se encontró el autor granadino.

El segundo poema cuya rima se mantiene igual en todos sus versos es la «Gacela del recuerdo del amor», en él la rima asonante en $e-o$ aparece de principio a fin:

No te lleves tu recuerdo.

Déjalo solo en mi pecho,

Temblor de blanco cerezo

en el martirio de enero.

Me separa de los muertos

un muro de malos sueños.

Doy pena de lirio fresco

para un corazón de yeso.

Toda la noche, en el huerto mis ojos como dos perros ${ }^{21}$.

Se advierte en esta gacela lorquiana, formada por dísticos, es decir, pareados asonantes, una cierta independencia sintáctica y

\footnotetext{
${ }^{19}$ En consonancia con lo que opinan críticos como Andrew A. Anderson, Mario Hernández y Emilio García Gómez, entre otros.

${ }^{20}$ Sin embargo, como explica Pierre Brunel, a pesar de que el elemento extranjero se vea sometido a modificaciones y adaptaciones, siempre remitirá a otra literatura, hará que el lector detenga su mirada en él y se cuestione su procedencia y su lugar en el texto. Véase BRUNEL, Pierre: «El hecho comparatista», cit., p. 33.

${ }^{21}$ Diván del Tamarit, edición crítica de Andrew A. Anderson, cit., pp. 208-210.
} 
semántica que recuerda a la de las gacelas y casidas árabes y persas. El poema posee una estructura muy diferente a la de otros que componen el Diván del Tamarit, pues está formado por pareados $^{22}$. Además, la rima, que es asonante, se mantiene siempre igual, como ya se ha adelantado anteriormente, y se puede observar de nuevo una cierta intención por parte del poeta de homenajear y recordar a los autores arábigo-andaluces y a su característica de terminar los versos con la misma letra. Así, en este poema los versos acaban en la vocal $o$, o en la consonante $s$. Y la rima asonante es siempre idéntica, en $e$ - $o$. Son estos, juntos con otros que aparecerán más adelante, rasgos que consiguen trazar un lazo de unión entre el Diván del Tamarit y la poesía árabe.

\section{El zéjel y la canción}

El zéjel es una composición formada por una estrofa inicial, seguida de otras estrofas compuestas cada una por tres versos monorrimos, seguidos de otro verso de rima consonante, igual a la del estribillo. Los arabistas lo consideran, junto con otras composiciones poéticas, el origen de la poesía estrófica europea $^{23}$. Lo más importante del zéjel es el cuarto verso, el cual posee una rima idéntica a la del estribillo, que se repite en el cuarto verso de todas las estrofas de la misma canción. Asimismo, le siguen seis estrofas formadas por tres elementos:

-Un trístico monorrimo, conocido como mudanza, con una rima distinta en cada estrofa.

-El verso de vuelta unisonante, con rima igual en todas las estrofas.

-El estribillo, donde se encuentra el tema de la composición.

El número de sílabas resulta indiferente en esta composición, al igual que ocurre en la qasida y en la gacela. Según explica Menéndez Pidal, lo único indispensable en el zéjel es la combinación de los tres versos monorrimos, de rima cambiante en cada estrofa y cada uno aparece seguido de otro verso de rima

\footnotetext{
${ }^{22}$ Son pareados por su distribución sintáctica y no por la rima, ya que esta se mantiene igual en todos los versos.

${ }^{23}$ Vernet, Juan: La cultura hispanoárabe, cit., p. 282.
} 
igual en todas las estrofas ${ }^{24}$. El metro más utilizado en la composición del zéjel es el octosílabo, junto con el hexasílabo ${ }^{25}$.

El poeta arábigo-andaluz Ibn Quzman fue el encargado de divulgar por toda al-Ándalus este tipo de poesía popular, donde se mezclaba el uso del árabe clásico con el vulgar, además de numerosos romancismos ${ }^{26}$. Sin embargo, no existe unanimidad en la lengua utilizada para el zéjel; así, Emilio García Gómez expone que era tan solo el árabe vulgar la lengua que se utilizaba y considera el zéjel una moaxaja ${ }^{27}$. A continuación, se pueden leer unos versos pertenecientes a uno de los zéjeles compuestos por el autor andalusí:

\author{
Dura carga es el amor. \\ ¡Quién pudiera resistir! \\ $¡$ A las almas, guapos, dad \\ vida y se os alabará! \\ Los secretos del amor \\ sólo están en el mirar. \\ Unos bellos ojos ves \\ con la magia de Babel, \\ $\mathrm{y}$ te roban la razón, \\ con tu aguante se te van, \\ y has de ver tu corazón \\ maniatado y en prisión. \\ Los sayones del amor \\ hallan luego allí un cordel, \\ por tender tu corazón \\ en mitad del campo, igual \\ que el leñero suele hacer \\ con tocones. Hay después \\ siempre YESCA, pedernal \\ y eslabón con que encender ${ }^{28}$.
}

\footnotetext{
${ }^{24}$ Menéndez Pidal, Ramón: Poesía árabe y poesía europea: con otros estudios de literatura medieval. Buenos Aires: Espasa-Calpe, 1955, pp. 15-19.

${ }^{25}$ PARAíso, Isabel: La métrica española, cit., pp. 297-301.

${ }^{26}$ Galmés De Fuentes, Álvaro: Romania arábica: estudios de literatura comparada árabe romance. Madrid: Real Academia de la Historia, 1999, p. 27.

${ }^{27}$ García Gómez, Emilio: El mejor Ben Quzmán en 40 zéjeles. Madrid: Alianza Editorial, 1998, p. 41.

${ }^{28}$ Iвn QuZman: «La hoguera del amor», ibid., pp. 87-89.
} 
Estos versos del zéjel de Ibn Quzman sirven de ejemplo para visualizar esa distribución estrófica y métrica de la que se viene hablando. En algunas de las composiciones poéticas del Diván del Tamarit se advierte una proliferación de los versos octosílabos, así como una distribución parecida a la de la canción popular, valiéndose incluso de un estribillo. En primer lugar, cabe destacar el siguiente poema, cuya versificación no resulta inconveniente comparar con la del zéjel quzmaní:

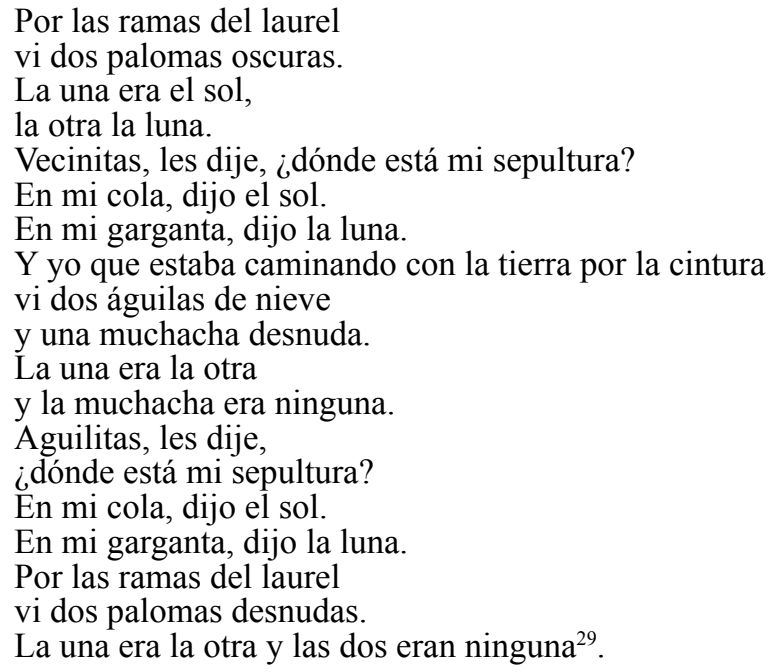

Se trata de unos versos de carácter arromanzado, pues proliferan los versos octosílabos y existe una tendencia al modelo de romance, que no siempre se cumple, pero que se advierte como paradigma en el texto. Como se puede observar, el verso octosílabo no está presente en todo el poema, sino que existe una polimetría. Hay también versos pentasílabos, heptasílabos y endecasílabos, característica esta que también puede tener el romance $^{30}$. El acercamiento hacia la métrica popular queda patente en ese uso del verso por parte del poeta granadino. Así, en

\footnotetext{
${ }^{29}$ García Lorca, Federico: «Casida de la palomas oscuras», en Diván del Tamarit, edición crítica de Andrew A. Anderson, cit., pp. 248-150.

${ }^{30}$ PARAíso, Isabel: La métrica española, cit., p. 162.
} 
este poema Lorca, valiéndose de una modificación muy propia del romance, utiliza la tradición lírica popular más genuina española, para aunarla con la arábigo-andaluza, de forma que ambas le sirvan al autor para recrear unas composiciones métricas en las que lo popular y tradicional se una con lo moderno. Lo moderno se encuentra aquí en el plano retórico, en el uso de las metáforas genuinamente lorquianas, enlazado con una versificación popular y tradicional. Por tanto, la antítesis -tan propia de la poética lorquiana- aparecerá también en su forma de aunar lo moderno y lo popular. Pero quizá donde más se pueda observar esa verdadera unión entre el canto popular-siempre tan presente en la poesía de Lorca- y la poética moderna, sea en la «Gacela del amor que no se deja ver», donde el poeta granadino inserta un estribillo, así como versos que hacen clara referencia a una canción popular infantil:

\author{
Solamente por oír \\ la campana de la Vela \\ te puse una corona de verbena. \\ Granada era una luna \\ ahogada entre las yedras. \\ Solamente por oír \\ la campana de la Vela \\ desgarré mi jardín de Cartagena. \\ Granada era una corza \\ rosa por las veletas. \\ Solamente por oír \\ la campana de la Vela \\ me abrasaba en tu cuerpo \\ sin saber de quién era ${ }^{31}$.
}

Según explica Mario Hernández en la introducción a su edición del Diván del Tamarit, Lorca incorpora dos versos de una copla granadina, homenajeando a su ciudad, cual poeta árabe:

$\overline{{ }^{31}}$ Diván del Tamarit, edición crítica de Andrew A. Anderson, cit., pp. 198-200. 
Quiero vivir en Graná solamente por oír la campana de la Vela cuando me voy a dormir.

Además, incluye también una canción perteneciente a un juego infantil conocido en España y, sobre todo, en Granada, que explica el origen del «jardín de Cartagena ${ }^{32} 》$. En algunas casidas árabes se añade un verso externo -llamado tadmin-, perteneciente a otro autor $\mathrm{u}$ otra obra, acomodándolo al metro y a la rima que posea el poema. Es esto lo que lleva a cabo el poeta granadino en su gacela.

Por otro lado, los cuartetos y los tercetos lorquianos no solo remiten a la canción popular, sino que recuerdan también a la estructura estrófica del zéjel. En definitiva, el zéjel estaba destinado para ser cantado en público, la propia palabra, zayal en árabe, significa «bailada», como expone Isabel Paraíso ${ }^{33}$. Por ello, la canción y él mantienen características comunes importantes.

Como sabemos, la música es de gran importancia en la poesía arábigo-andaluza, igualmente, en García Lorca es clara la referencia musical en muchos de sus poemas, como ocurre, por ejemplo, en la «Gacela del mercado matutino», donde la relación de versos octosílabos y heptasílabos deja clara la conexión con la canción popular:

Por el arco de Elvira

Quiero verte pasar,

para saber tu nombre

y ponerme a llorar.

¿Qué luna gris de las nueve

te desangró la mejilla?

¿Quién recoge tu semilla

de llamarada en la nieve?

¿Qué alfiler de cactus breve

asesina tu cristal?...

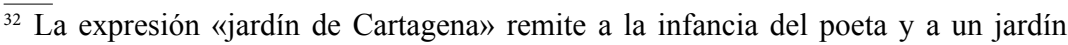
perdido, visto como el edén, lo cual conecta también con la filosofía e imaginería hispano-árabe (HERNÁNDEZ, Mario: «Introducción» a García Lorca, Federico: Diván del Tamarit. Llanto por Ignacio Sánchez Mejías. Sonetos, edición, introducción y notas de Mario Hernández. Madrid: Alianza Editorial 1981, pp. 25-27).

${ }^{33}$ PARAíso, Isabel: La métrica española, cit., p. 297. 


\begin{abstract}
Por el arco de Elvira voy a verte pasar, para beber tus ojos y ponerme a llorar.
\end{abstract}

¡Qué voz para mi castigo levantas por el mercado! ¡Qué clavel enajenado en los montones de trigo!

¡Qué lejos estoy contigo, qué cerca cuando te vas!

Por el arco de Elvira voy a verte pasar, para sentir tus muslos y ponerme a llorar ${ }^{34}$.

La repetición constante del estribillo le sirve al autor granadino para representar también, a través de su estructura y composición métrica, la ansiedad ante la presencia de la persona amada. La novedad se encuentra en el tercer verso de cada estribillo, donde la acción que lleva a la voz poética al llanto es distinta y, además, el verso resulta sin rima. Pero todas esas acciones son trágicas y hunden al amante en una angustiosa ansiedad que se corresponde con la misma que intenta hacer sentir el poeta al introducir ese estribillo.

\title{
La recurrencia paralelística en la poesía árabe andalusí y en Diván del Tamarit
}

En la poesía árabe cada verso es de manera formal -intrínsecamente- paralelístico y este supone un procedimiento rítmico característico y habitual. Puesto que cada verso se encuentra dividido en dos partes por medio de una cesura, se puede hablar de un paralelismo interno dentro del sistema rítmico de la poesía árabe y persa. De manera que la base rítmica queda apoyada y sustentada en el recurso paralelístico.

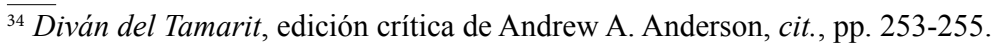




$$
\begin{aligned}
& \text { لا تبكين من الليالي انها حرمتك نغبة شارب من مشرب }
\end{aligned}
$$

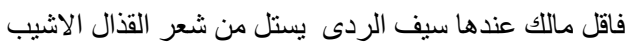

$$
\begin{aligned}
& \text { ورحيل عيشك كل رحلة ساعة وفناء طيبك في الزمان الاطيب } \\
& \text { فاذا بكيب فبك عمرك إنه زجل الجناح يمر مر الكوكب } 35
\end{aligned}
$$

De nuevo, conviene recoger los versos en versión original con el fin de poder apreciar ese paralelismo interno que contiene la métrica árabe, el cual contribuye de manera considerable al ritmo específico del poema. Según Isabel Paraíso, hay dos tipos de paralelismo en la poesía bíblica hebrea: uno es el semántico y otro el estructural, en el que se advierten semejanzas sintácticas entre los miembros o entre las líneas ${ }^{36}$. En el poema de Ibn Suhayd -al igual que ocurre con la poesía árabe clásica y la persa-, el paralelismo que se aprecia es estructural, responde a la estructura externa y a la distribución formal de cada verso, aunque también existe una estructura interna paralelística que responde al sentido de cada verso. De manera visual, la cesura que aparece en medio de cada verso es la encargada de hacer evidente ese paralelismo del que se viene hablando.

En la métrica española, por influencia gallego-portuguesa, el paralelismo ha servido de base rítmica durante los siglos XIII y XIV. Así, en las cantigas es notable el recurso del paralelismo, el cual puede ser, según Carlos Alvar y Ángel Gómez Moreno, de distintos tipos: «paralelismo de ideas, que se limita a desarrollar de forma progresiva los motivos contenidos en la primera estrofa, o a repetir en todas las estrofas el mismo motivo, aunque con distintas modulaciones. Hay un paralelismo formal, que se basa en la repetición de los mismos contenidos en cada una de las estrofas de su composición, con la repetición sistemática de vocablos y giros sintácticos ${ }^{37} \gg$.

En Federico García Lorca el recurso del paralelismo aparece de manera sistemática a lo largo de toda su obra poética. Así, se

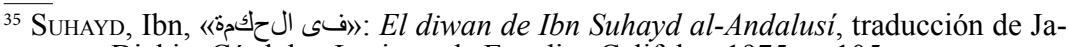
mes Dickie. Córdoba: Instituto de Estudios Califales, 1975, p. 105.

${ }^{36}$ PARAíso, Isabel: La métrica española, cit., p. 30.

${ }^{37}$ Alvar, Carlos, y Gómez Moreno, Ángel: La poesía lírica medieval. Madrid: Taurus, 1988, pp. 63 у 64. 
puede apreciar ya en varias de sus primeras poesías de juventud:

Quisiera estar en tus labios para apagarme en la nieve de tus dientes.

Quisiera estar en tu pecho para en sangre deshacerme.

Quisiera en tu cabellera de oro soñar para siempre ${ }^{38}$.

Se trata de un paralelismo formal, pues la repetición se encuentra en la estructura sintáctica de la oración cuya palabra introductoria es el verbo «querer», mediante esta repetición el autor consigue marcar un ritmo dentro del poema. Además, se reitera un mismo concepto, que es el deseo de la voz poética por unirse con la persona amada. Estos versos son una pequeña muestra de cómo el poeta granadino ya en su juventud recurría al paralelismo formal en muchas de sus composiciones. Asimismo, en el Diván del Tamarit son numerosas las ocasiones en las que aparece este recurso formal. El poeta se apoya en él, no solo para marcar un ritmo específico y aportar una musicalidad determinada al poema, sino también para representar de manera formal -junto con la antítesis- lo expresado por la voz poética:

Yo quiero que el agua se quede sin cauce.

Yo quiero que el viento se quede sin valles.

Quiero que la noche se quede sin ojos y mi corazón sin la flor del oro;

que los bueyes hablen con las grandes hojas y que la lombriz se muera de sombra; que brillen los dientes de la calavera y los amarillos inunden la seda ${ }^{39}$.

\footnotetext{
${ }^{38}$ GARcía Lorca, Federico: «Madrigal apasionado», en Poesía inédita de juventud, edición de Christian de Paepe, prefacio de Marie Laffranque. Madrid: Cátedra, 2008, pp. 559 y 560.

${ }^{39}$ García Lorca, Federico: «Gacela de la terrible presencia», en Diván del Tamarit, edición crítica de Andrew A. Anderson, cit., pp. 193, 194 y 195.
} 
En este poema compuesto por dísticos, como es habitual en la poética lorquiana, los recursos formales y los tópicos, es decir la forma y el contenido, van unidos y le sirven a Lorca para poder expresar lo que desea. En la gacela señalada, la voz poética se muestra angustiosa ante la presencia de la persona amada, se advierte una ansiedad ante el propio amor y ello se traduce en los recursos formales utilizados por el poeta granadino. En este caso, el paralelismo - de la mano de la antítesis- refuerza esa idea y crea un ritmo en el poema que revela la ansiedad y la angustia del amante. Es importante tener en cuenta, en este sentido, el hecho de que en García Lorca a menudo el paralelismo aparece unido a la antítesis, resultando así un paralelismo antitético, como se puede apreciar en la «Gacela de la terrible presencia.»"

En definitiva, Federico García Lorca utiliza a lo largo de toda su poética el paralelismo, con especial atención al paralelismo antitético, y recoge también el cancionero gallego, donde, como se ha comentado con anterioridad, el paralelismo tiene tanta importancia. Asimismo, no es casualidad que en la misma época Lorca escribiera su libro Seis poemas galegos.

Volviendo al Diván del Tamarit, se puede trazar una conexión con la poesía árabe clásica, concretamente con la árabe andalusí, así como con la persa, puesto que en ambas el recurso formal del paralelismo se encuentra en la base rítmica de su poesía, como se ha visto. Desde luego, no se puede afirmar que García Lorca utilice el paralelismo en su Diván del Tamarit siguiendo sin más la retórica de los poetas árabes de al-Ándalus, puesto que el paralelismo es una formulación retórica que, como se ha visto, se encuentra en el poeta granadino desde sus inicios y responde a ese deseo de ahondar en la tradición cancioneril y popular, característica importante de la poética lorquiana. No obstante, sí se aúnan en el Diván diversos aspectos que permiten hacer una lectura en la que son claras las huellas orientales: la utilización de la rima única en algunos poemas, el uso frecuente del pareado, el empleo intencionado de estructuras paralelísticas complementarias a las agrupaciones estróficas, el recurso al estribillo, etc. Aunque son elementos que pueden aparecer también en la tradición occidental, a veces por influjo árabe, no se puede negar la consciente recreación lorquiana de la tradición oriental. 


\section{Conclusiones}

Como ya se ha dicho a lo largo del artículo, no se puede hablar de una imitación de la literatura árabe andalusí por parte de García Lorca. Por ello, no se habla en este trabajo comparatista de «influencia» en un sentido mecanicista que presuponga una obra o unos escritores que sirvan de modelo y sean seguidos claramente desde un punto de vista formal o temático. En consonancia con las ideas de Claudio Guillén, se ha preferido matizar siempre este término o bien obviarlo por tratarse de una palabra cargada de connotaciones bastante positivistas.

Puede afirmarse que el Diván del Tamarit es un ejercicio de homenaje por parte de García Lorca hacia una cultura que despertaba en él gran interés y simpatía, aunque manteniendo siempre las cualidades estilísticas propias de la poética y la cosmovisión lorquiana.

El Diván del Tamarit no es, pues, estrictamente un diwān árabe o persa. El lector no puede esperar encontrar en él una reproducción de las composiciones métricas ni de la manera de poetizar andalusí. García Lorca asimila solo una terminología poética para ofrecer al lector una evocación y un marco de referencia y realizar una recreación original que es, al mismo tiempo, un homenaje.

Como en otras obras lorquianas, en el Diván del Tamarit es apreciable la asimilación de varias tradiciones literarias, característica de gran importancia en la actividad creadora de Federico García Lorca y, en general, de todos los grandes escritores. El objetivo lorquiano es volver la vista hacia el pasado, tener en cuenta las tradiciones literarias que no deben olvidarse, pues contribuyen a la literatura del presente, y conjugar el pasado con el presente y el futuro. Es la inmersión y la inclusión de una obra literaria en una tradición poética de la que no puede desasirse, pues es parte de su historia literaria. Es esto lo más importante que hay que tener en cuenta con respecto a la métrica lorquiana y es la razón por la que Federico García Lorca realiza un diván: para lograr unas composiciones donde lo popular y lo tradicional convivan con lo moderno. 


\section{Bibliografía utilizada}

\section{Obras de autores árabes y persas}

GARCÍA GÓMEZ, Emilio: Poemas arábigo-andaluces. Madrid: EspasaCalpe 1959 ( $4^{\mathrm{a}}$ ed.).

-(ed.): El mejor Ben Quzmán en 40 zéjeles. Madrid: Alianza Editorial, 1988.

SUHAYD, Ibn: El diwan de Ibn Suhayd al-Andalusí, traducción de James Dickie. Córdoba: Instituto de Estudios Califales, 1975.

VEGLISON ELÍAS DE MOLINS, Josefina (ed.): La poesía árabe clásica. Madrid: Hiperión, 1997.

ZAYDUN, Ibn: Poesías, edición y traducción de Mahmud Sobh. Madrid: Clásico Hispano-Árabes bilingües, nº 2, 1985.

\section{Obras de Federico García Lorca}

-Diván del Tamarit. Llanto por Ignacio Sánchez Mejías. Sonetos, edición, introducción y notas de Mario Hernández. Madrid: Alianza Editorial 1981.

- Canciones y Primeras canciones, edición crítica de Piero Menarini. Madrid: Espasa Calpe, 1986.

-Diván del Tamarit. Seis poemas galegos. Llanto por Ignacio Sánchez Mejías, edición crítica de Andrew A. Anderson. Madrid: Espasa-Calpe, 1988.

- Poesía inédita de juventud, edición de Christian de Paepe, prefacio de Marie Laffranque. Madrid: Cátedra, 2008.

\section{Estudios}

ALVAR, Carlos: «Poesía culta y tradicional», en Pedro M. Piñero Ramírez (ed.): Lírica popular / Lírica tradicional. Lecciones en homenaje a D. Emilio García Gómez. Sevilla: Universidad de Sevilla, Fundación Machado, 1998, pp. 99-111.

ALVAR, Carlos, y GÓMEZ MORENO, Ángel: La poesía lírica medieval. Madrid: Taurus, 1988.

BACKĖS, Jean-Louis: «Poética comparada», en Brunel, Pierre y Chevrel, Yves (ed.): Compendio de Literatura Comparada. México: Siglo XXI, 1994, pp. 51-70.

BRUNEL, Pierre: «El hecho comparatista», en Brunel, Pierre y Chevrel, Yves (ed.), Compendio de Literatura Comparada. México: Siglo XXI, 1994, pp. 21-50

BRUNEL, Pierre y CHEVREL, Yves (ed.): Compendio de Literatura Comparada. México: Siglo XXI, 1994.

CERNUDA, Luis: Poesía española contemporánea. Madrid: Guadarrama, 1975.

DOMÍNGUEZ CAPARRÓS, José: Métrica española. Madrid: Síntesis, 2000. 
GALMÉS DE FUENTES, Álvaro: Romania arábica: estudios de literatura comparada árabe romance. Madrid: Real Academia de la Historia, 1999.

GONZÁLEZ PALENCIA, Ángel: «La poesía arábigo andaluza y su influencia». Revista Hispánica Moderna, 1935, I, 2, pp. 81-96.

GUILLÉN, Claudio: Entre lo uno y lo diverso. Barcelona: Tusquets, 2005.

HERNÁNDEZ, Mario: «Huellas árabes en el Diván del Tamarit», Ínsula, septiembre 1977, XXXII, 370, pp. 3 y 5.

- «Introducción» a Federico García Lorca: Diván del Tamarit. Llanto por Ignacio Sánchez Mejías. Sonetos, edición, introducción y notas de Mario Hernández. Madrid: Alianza Editorial 1981, pp. 9-50.

MENÉNDEZ PIDAL, Ramón: Poesía árabe y poesía europea: con otros estudios de literatura medieval. Buenos Aires: Espasa-Calpe, 1955.

NAVA, Gaspar María de, Conde de Noroña, (ed. y tr.): Poesías asiáticas. París: Julio Didot Major, 1833; segunda edición, Madrid: Biblioteca Universia, 1882.

PARAÍSO, Isabel: La métrica española en su contexto románico. Madrid: Arco / Libros, 2000.

PIÑERO RAMÍREZ, Pedro M. (ed.): Lírica popular / Lírica tradicional. Lecciones en homenaje a D. Emilio García Gómez. Sevilla: Universidad de Sevilla, Fundación Machado, 1998.

QUILIS, Antonio: Métrica española. Barcelona: Ariel, 2009.

TORRE, Esteban: El ritmo del verso (Estudios sobre el cómputo silábico y la distribución acentual, a la luz de la Métrica comparada, en el verso español moderno). Murcia: Universidad de Murcia, 1999.

- Métrica española comparada. Sevilla: Universidad, 2001.

VERNET, Juan: Literatura árabe. Barcelona: Labor, 196?

- La cultura hispanoárabe en Oriente y Occidente. Barcelona: Ariel Historia, 1978. 